\title{
Formação Médica na Estratégia de Saúde da Família: Percepções Discentes
}

\author{
Medical Training in the Family Health \\ Strategy: Student's Perceptions
}

José Roberto Bittencourt Costal Valéria Ferreira Romano ${ }^{I I}$ Rosane Rodrigues Costa ${ }^{l}$ Rodrigo Roger Vitorino

Luiz Anastácio Alves ${ }^{I I I}$ Andréia Patrícia Gomes ${ }^{I V}$ Rodrigo Siqueira-Batista ${ }^{I V}$

\author{
PALAVRAS-CHAVE \\ - Saúde da Família. \\ - Aprendizagem. \\ - Estudantes de Medicina. \\ - Educação Médica
}

Recebido em: 07/09/2011

Reencaminhado em: 05/05/2012

Aprovado em: 19/08/2012

REVISTA BRASILEIRA DE EDUCAÇ̃̃o MÉDICA

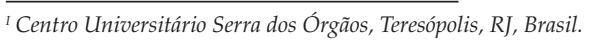

"I Universidade Federal do Rio de Janeiro, Rio de Janeiro, RJ, Brasil.

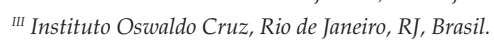

IV Universidade Federal de Viçosa, Minas Gerais, MG, Brasil.

\section{RESUMO}

Diante das atuais demandas sociais, tornou-se imprescindível para a educação médica a transição do modelo tradicional de formação reducionista e hospitalocêntrica para uma vertente de educação mais ampla e integralizada. A construção de novas práticas de formação em saúde - com a utilização de cenários externos -, em coparticipação com o SUS, tem assumido um papel fundamental na formação médica. Em 2005, o Centro Universitário Serra dos Órgãos (Unifeso) incorporou em seu currículo a Aprendizagem Baseada em Problemas e a inserção dos graduandos de Medicina em Unidades Básicas de Saúde da Família. Este artigo apresenta a percepção dos discentes de Medicina neste cenário. Para isto, realizou-se uma pesquisa qualitativa, utilizando-se entrevistas e análise temática das respostas, com a criação de categorias. Os resultados demonstram a combinação de impressões positivas - integração entre teoria e prática - e negativas — problemas na organização das atividades e necessidade de identificação de um preceptor local. Propõe-se um planejamento orientado pelas novas diretrizes para o ensino na Atenção Primária à Saúde, contextualizada à condição da integralidade.

Given current social demands, it has become essential for medical education to break from the traditional model of biological reductionist and training based only at hospitals and redefine itself towards a holistic care (integrality). The construction of new training practices in health with the use of new outdoor scenarios, in partnership with (Unified National Health System - SUS), assumed a key role. In 2005 the Centro Universitário Serra dos Órgãos (Unifeso) incorporated into its curriculum the Problem-Based Learning and the insertion of medical undergraduates into Basic Health Units Family. This paper describes the perception of medical students in this scenario. We conducted a qualitative research working from the application of interviews and the utilization of thematic analysis of responses with the creation of categories. The results show the combination of positive impressions - integration between theory and practice - and negative — problems in the organization of activities, as well as the necessity to identify a local preceptor. A plan is proposed, guided by the new Directives, for teaching in the primary health care in the context of the condition of integrality. 


\section{INTRODUÇÃO}

Desde meados dos anos 1980, a reforma do setor saúde - particularmente nos âmbitos do processo de trabalho, da gestão e da formação de recursos humanos - vem se desenvolvendo no Brasil e na maioria dos demais países da América Latina. A necessidade de modificações nesta esfera é reconhecida com críticas ao aparelho formador -, concentrando-se principalmente na educação médica, embora também inclua a formação dos demais profissionais de saúde ${ }^{1,2}$.

A organização dos serviços de saúde deveria ser estabelecida no sentido de oferecer respostas aos problemas de saúde e de sofrimento das pessoas, como afirma Lampert ${ }^{2}$, ao defender que "as escolas médicas foram criadas para preparar profissionais que atuando nestes serviços possam oferecer soluções a estes problemas e às necessidades de saúde" (p. 90). Entretanto, percebe-se que, para alcançar esta condição, são necessárias mudanças na formação do perfil do médico, na graduação e na pós-graduação (residência médica). Desta forma, conclui que as transformações necessárias ao setor saúde estão "intrinsecamente ligadas à formação de recursos humanos, particularmente da categoria médica, uma vez que ela é ainda a detentora da hegemonia ideológica da prática profissional do setor" (p. 90)².

Frente às novas demandas sociais que se descortinam perante o Sistema Único de Saúde (SUS) e reconhecendo a necessidade de redefinições em seus recursos humanos, admite-se que uma nova adequação dos modos de ensino é igualmente imprescindível para que se possa atender melhor aos interesses e carências destes serviços ${ }^{3}$. Feuerwerker ${ }^{4}$ considera que a partir dos conflitos na atenção à saúde foi verificada a necessidade de modificações no ensino médico e, consequentemente, do projeto político-pedagógico das universidades, incluindo a concepção do mundo, as relações sociais, o conhecimento a ser construído pelos egressos e a metodologia empregada.

Como elemento para uma reflexão acerca das modificações sugeridas para uma nova dimensão de formação e atuação de recursos humanos na área da saúde, pode-se citar a imagem/conceito do "quadrilátero da formação para a área da saúde", que Ceccim et al. ${ }^{5}$ idealizaram ao incluírem ensino, gestão setorial, práticas de atenção e controle social — articulados de forma indissociável - numa política educacional que protagonize e permeie processos interativos e de ação na realidade, com o objetivo de transformar, negociar e detectar caminhos e processos perante as demandas individuais, coletivas e institucionais. Esse quadrilátero englobaria sentidos estéticos, organizacionais, éticos e tecnológicos, com a responsabilidade de intermediar atos que possibilitem novos arranjos educativos e pedagógicos no cuidado à saúde e que sejam passíveis de reavaliação e contextualização constantes. Os autores ressaltam o papel fundamental da Educação Permanente neste contexto e do privilégio que deve ser concedido ao SUS na interlocução com as instituições em seus projetos pedagógicos de formação profissional, de forma a situá-lo muito além de um simples campo de prática ou aprendizagem profissional, sobretudo como formulador de uma real educação em serviço ${ }^{5}$.

Percebe-se, portanto, como afirma Feuerwerker", que "a mudança necessária na educação médica — e nos profissionais de saúde - é complexa e exige aprofundamento do debate político-conceitual, não usual no campo" (p. 17). Marins ${ }^{6}$ endossa esta complexidade ao ressaltar ainda outros aspectos a serem cumpridos para a transformação do perfil destes profissionais: "as modificações no processo de trabalho dependem intimamente das competências, das habilidades e da adoção de valores éticos, sociais e culturais dos profissionais" (p. 100).

Desta forma, a necessidade de reestruturação do modelo de atenção à saúde acabou por evidenciar a atual fragilidade e inadequação do ensino das escolas médicas diante das reais necessidades da população brasileira: o médico ainda se mostra despreparado para exercer seu trabalho numa perspectiva de atenção à saúde integral, que considere os aspectos biopsicossocioambientais e a prestação de cuidados equânime ${ }^{7}$. Cabe ressaltar a importância da formação e da atuação dos profissionais na área da saúde, e em particular do estudante de Medicina, a partir da perspectiva da integralidade do cuidado. Koffman et al. ${ }^{8}$ consideram que as práticas de avaliação da formação e do cuidado são interdependentes. Qualquer projeto político-pedagógico, método ou estratégia de ensino adotado pelas escolas médicas que não incorpore o campo do cuidado em saúde e a centralidade do usuário junto ao seu processo avaliativo é compreendido como estratégia de baixo potencial para alterar a lógica hegemônica da atual organização do trabalho educacional em saúde ${ }^{9}$. Estes aspectos são seminais para a construção de linhas de cuidado que superem os modelos tradicionais de formação que não contextualizam as unidades produtoras de cuidado e seus ricos contextos socioculturais e que possibilitem o envolvimento do currículo em questões da realidade, tornando-o efetivamente integral ${ }^{8}$.

Ceccim et al..$^{10}$ defendem, ainda, que a prática clínica pode ser pensada - e exercida — como espaço de resistência e criação na educação dos profissionais da saúde, para a "afirmação da vida". Os autores compreendem que o ideário científico contextualizado no modelo biomédico reducionista - e, em certo sentido, mecanicista ${ }^{11}$ - e na especialização corporativista - em oposição às humanidades — retirou a afetividade do campo da saúde e instituiu a normatividade: estar saudável 
aproximou-se de padrões estatísticos (na interseção dos debates entre acaso e necessidade $)^{12} \mathrm{e}$ da prática que privilegia a medicalização em contraposição à alteridade ou ainda ao "encontro com o outro" e sua subjetividade. A "afirmação" da vida seria, na acepção desse autor, a "autopoesis da existência" - termo que designaria, de acordo com Maturana e Vare$1 a^{13}$, a capacidade dos seres vivos de produzirem a si mesmos — em contraposição à tecnicidade da vida13,14. Já a "resistência" significaria a heteronomia dos usuários, tendo o cenário produtor de saúde a responsabilidade da "criação", principalmente de novidades estéticas e de tecnologias leves. A partir dessas premissas, Ceccim et al. defendem que a noção de integralidade e humanização dos profissionais de saúde pode ser estabelecida ${ }^{10}$.

A integralidade do cuidado é ainda extensamente abordada em coletânea de textos que relatam "as experiências de ensino na formação de profissionais para a integralidade em saúde", em Ensino-trabalho-cidadania: novas marcas ao ensinar integralidade no SUS"15, lançado em 2004 no Seminário Nacional sobre Política AprenderSUS e as Graduações na Saúde, que teve o intuito de socializar os diferentes espaços-tempos de cada ator e de suas práticas de ensino na formação da força de trabalho em saúde a partir da tríade educação-trabalho-cidadania e de sua representação e intencionalidade: integrar universidade e sistema de saúde. O evento contou com a parceria do Laboratório de Pesquisa sobre práticas da Integralidade em Saúde (Lappis) e com o apoio do Instituto de Medicina Social (IMS) da Universidade do Estado do Rio de Janeiro (Uerj). Os títulos, temas estudados (grifados em itálico) e a análise e considerações de cada um destes textos, organizados regionalmente, encontram-se no Quadro $1^{16-25}$. Nota-se que tais experiências - assim como aquela protagonizada pelo Unifeso e objeto deste estudo - guardam em comum o papel de (re) construção permanente de novas práticas de formação em saúde, na perspectiva da integralidade do cuidado e no contexto de instituições de ensino cujos projetos pedagógicos estabelecem interfaces com cenários externos - especialmente a Estratégia Saúde da Família - com a participação do SUS. Neste contexto, tem-se como objetivo fundamental o resgate do lado humano e a afirmação da vida.

Além deste livro, destaca-se ainda na esfera da integralidade e do papel do SUS nos cursos de graduação na área da saúde, o texto Ensinar saúde: a integralidade e o SUS nos cursos de graduação na área de saúde (Pinheiro et al. ${ }^{26}$. Seus autores ressaltam que a motivação dessa publicação foi oferecer contribuições para o desenvolvimento de práticas educativas "mais porosas aos contextos da vida" e, portanto, potencialmente "capazes de formar profissionais imbuídos de práticas cuida- doras em saúde com respeito à pluralidade e à singularidade dos processos de viver" (p. 9) ${ }^{26}$. Afirmam que o SUS, ao organizar práticas sob a ótica da integralidade, possibilita às instituições de ensino o exercício de valores democráticos ${ }^{27}$, pois distingue a noção de "trabalho" da de "serviço", uma vez que possibilita a integração da gestão e controle social e, por extensão, a percepção dos direitos sociais e políticos a partir das práticas e saberes em cenários vivos de ensino-aprendizagem $^{15,26}$. Duas experiências, realizadas distintamente na Universidade Federal Fluminense (UFF) e na Universidade do Estado do Rio de Janeiro (Uerj), chamam a atenção sobre o ensino em saúde orientado pela integralidade. As mesmas se encontram sintetizadas no Quadro $2^{28,29}$.

Com base na pluralidade de referências aqui mencionadas, percebe-se o quanto é necessário que o ensino - sobretudo no que diz respeito à medicina - assuma um desenho de prática social, delegando a si próprio o propósito de instaurar uma prática na qual a produção de conhecimento, a formação acadêmica e a prestação de serviços sejam indissociáveis ${ }^{30}$. Com base nestas premissas, seria promovido no aluno o engajamento para compreender a dinâmica social e a utilização deste conhecimento como instrumento de excelência profissional $^{11-35}$, como defendido no perfil do médico proposto pelas Diretrizes Curriculares Nacionais do Curso de Graduação em Medicina $(\mathrm{DCN})^{36}$ :

[almeja-se] "um médico, com formação generalista, humanista, crítica e reflexiva; capacitado a atuar, pautado em princípios éticos, no processo de saúde-doença e seus diferentes níveis de atenção, com ações de promoção, prevenção, recuperação e reabilitação à saúde, na perspectiva da integralidade da assistência, com senso de responsabilidade social e compromisso com a cidadania, como promotor da saúde integral do ser humano."(p. 38)

Nesse contexto, a diversificação dos cenários de ensino-aprendizagem figura como eixo educacional de uma medicina mais próxima da sociedade e mais influente no panorama regional, como já demonstrado. Aqui, o SUS atua como agente essencial neste processo, por intermédio das unidades de atenção à saúde - mormente as Unidades Básicas de Saúde da Família (UBSF) -, as quais, segundo a Associação Brasileira de Educação Médica (Abem) e as DCN, devem receber os graduandos logo nos primeiros semestres do curso. Algumas características peculiares da Atenção Primária à Saúde (APS) ou Atenção Básica de Saúde (ABS) — justificam sua utilização como cenário de aprendizagem médica: (a) a potencial resolução de até $80 \%$ dos problemas de saúde da população; (b) sua 


\section{QUADRO 1}

Títulos, tema estudado (em itálico) e considerações dos textos agrupados regionalmente publicados em "Ensino-trabalhocidadania: novas marcas ao ensinar integralidade no SUS" (Pinheiro et al., 2006) ${ }^{15}$

\begin{tabular}{|c|c|c|}
\hline \multicolumn{3}{|c|}{ Textos } \\
\hline Região & Título - tema estudado & Considerações \\
\hline Norte & $\begin{array}{l}\text { "Saúde da Família no Curso de Medicina da } \\
\text { Universidade Federal do Acre" - Inserção dos alunos da } \\
\text { graduação na Atenção Básica durante três anos }\end{array}$ & $\begin{array}{l}\text { Luta para a ruptura do corporativismo e da primazia } \\
\text { do status médico e da visão tecnicista, matizada por } \\
\text { tons neoliberais. } \\
\text { Tentativa de reconhecimento das especificidades } \\
\text { sociais, diagnósticos socioambientais, promoção à } \\
\text { saúde e exercício da clínica na atenção básica }{ }^{16} \text {. }\end{array}$ \\
\hline Nordeste & $\begin{array}{l}\text { "O desafio da construção de marcos teóricos e } \\
\text { metodológicos (re)orientadores da produção da força } \\
\text { de trabalho de enfermagem no espaço da Faculdade de } \\
\text { Enfermagem (Faen)" — Socialização, marcos teóricos e } \\
\text { metodológicos na força de trabalho da enfermagem na } \\
\text { perspectiva das necessidades sociais } \\
\text { "A Saúde da Família na Faculdade de Medicina de } \\
\text { Juazeiro do Norte" — Formação de médicos com perfil } \\
\text { adequado às necessidades do SUS }\end{array}$ & $\begin{array}{l}\text { Conversação sobre o papel da universidade para além } \\
\text { da qualificação técnica e científica, situando-a no } \\
\text { exercício da reflexão ética e política no trabalho em } \\
\text { saúde. } \\
\text { Práticas fundadas na cidadania e no estabelecimento de } \\
\text { valores éticos, com a formação de profissionais } \\
\text { reflexivos e dotados de espírito crítico }{ }^{17,18} \text {. }\end{array}$ \\
\hline Centro-Oeste & $\begin{array}{l}\text { "Interação Ensino-Serviço-Comunidade, uma } \\
\text { ferramenta para a integralidade" - Ensino orientado } \\
\text { para a comunidade com estudantes do curso de Psicologia da } \\
\text { Uniderp* durante dez semestres }\end{array}$ & $\begin{array}{l}\text { Possível reconfiguração de um currículo } \\
\text { multidisciplinar, a partir de novos cenários para os } \\
\text { processos de ensino-aprendizagem do trabalho em } \\
\text { saúde, com formação de profissionais sensíveis às } \\
\text { necessidades do } \text { SUS }^{19} \text {. }\end{array}$ \\
\hline Sudeste & $\begin{array}{l}\text { "Em busca da recomposição da arte do cuidado e do } \\
\text { fazer/aprender: a interação universidade, serviço e } \\
\text { comunidade na Faculdade de Medicina de Botucatu/ } \\
\text { Unesp" } \\
\text { "Travessia a caminho da integralidade: uma experiência } \\
\text { do curso de Odontologia da UFMG" } \\
\text { "Experiências da integralidade no curso de graduação } \\
\text { da Escola de Enfermagem da Universidade Federal de } \\
\text { Minas Gerais" } \\
\text { Os três textos refletem sobre as mudanças nos respectivos } \\
\text { cursos ao incorporarem novos cenários de ensino com a } \\
\text { interação entre diversos atores }\end{array}$ & $\begin{array}{l}\text { A educação problematizadora pode ser empregada } \\
\text { como estratégia metodológica de ensino-aprendizagem. } \\
\text { A inserção em novos cenários — tais como as unidades } \\
\text { básicas de saúde - é capaz de oferecer práticas } \\
\text { voltadas para a integralidade das ações em saúde, com } \\
\text { a respectiva valorização das dimensões psicossociais } \\
\text { nas atividades educativas, visando à formação de } \\
\text { profissionais sensíveis às demandas dos usuários do } \\
\text { SUS }{ }^{20,21,22} \text {. }\end{array}$ \\
\hline Sul & $\begin{array}{l}\text { "Projeto de Assistência Interdisciplinar ao Idoso em } \\
\text { nível primário (Painp): a busca de uma prática } \\
\text { possível" } \\
\text { "Diagnóstico de saúde em unidade de saúde da família } \\
\text { como ferramenta prática pedagógica" } \\
\text { "Uma proposta inovadora de formação de profissional } \\
\text { em fisioterapia centrada na integralidade em saúde" } \\
\text { Os três textos apresentam propostas de transformação do } \\
\text { ensino a partir da perspectiva da integralidade }\end{array}$ & $\begin{array}{l}\text { Identificação do processo saúde-doença e do } \\
\text { envelhecimento para além da mera perspectiva } \\
\text { curativa, destacando o exercício da promoção à saúde. } \\
\text { Possibilidade de criar reflexões sobre a prática da } \\
\text { integralidade em novos cenários a partir de diferentes } \\
\text { cursos da área de saúde. } \\
\text { Atuação além da visão estritamente organicista e } \\
\text { reducionista do corpo. } \\
\text { Conhecimento da realidade sociocultural, política, } \\
\text { econômica e sanitária e ambiental } \\
23,24,25\end{array}$ \\
\hline
\end{tabular}

*Uniderp - Universidade para o Desenvolvimento do Estado e da Região do Pantanal-Campo Grande (MS). 


\section{QuAdRo 2}

Títulos, temas e considerações das experiências publicadas em Ensinar saúde: a integralidade e o SUS nos cursos de graduação na área de saúde (Pinheiro et al., 2006) ${ }^{26}$

\begin{tabular}{|c|c|}
\hline Experiência: título - tema & Consideraçôes \\
\hline $\begin{array}{l}\text { "Transformação na graduação de enfermagem da Uerj" - Criação } \\
\text { de uma concepção pedagógica crítica com reformulação curricular }\end{array}$ & $\begin{array}{l}\text { Modificações no modelo de formação do enfermeiro, tendo em } \\
\text { vista a produção social da saúde e a implementação de um } \\
\text { currículo integrado com superação do modelo mecanicista e } \\
\text { funcionalista em novos cenários de aprendizagem. Implantado } \\
\text { desde o final dos anos } 1990 \text { em processo contínuo de revisão }{ }^{28} \text {. }\end{array}$ \\
\hline $\begin{array}{l}\text { "O currículo de Medicina da Universidade Federal Fluminense: } \\
\text { revisitando uma experiência" - Reflexões sobre experiências de } \\
\text { mudança na formação de profissionais de saúde a partir da inovação } \\
\text { curricular }\end{array}$ & $\begin{array}{l}\text { Realizada a partir de parceria entre a Lupa-Saúde*, o Departamento } \\
\text { de Planejamento em Saúde do Instituto de Saúde da Comunidade } \\
\text { da UFF e o Lappis-Uerj. } \\
\text { Traz reflexões sobre a integralidade e o ideário da reforma sanitária. } \\
\text { Propõe a ruptura do ciclo básico-tradicional e do contato tardio com } \\
\text { a realidade durante a graduação. Trabalha com a inserção em novos } \\
\text { cenários, como o Programa Médico de Família e as Policlínicas } \\
\text { Comunitárias. } \\
\text { Construção da linha de pesquisa EnsinaSUS²9. }\end{array}$ \\
\hline
\end{tabular}

* Laboratório Universitário de Planejamento em Saúde.

organização como local de acolhimento à demanda e de busca ativa de pacientes com avaliação de vulnerabilidade; (c) a possibilidade genuína de exercer uma saúde coletiva ao se empregar o conceito de clínica ampliada, ultrapassando a concepção biomédica em direção aos aspectos subjetivos, sociais e ambientais de cada sujeito ${ }^{36-42}$.

O Centro Universitário Serra dos Órgãos (Unifeso), situado em Teresópolis (RJ), em consonância com as transformações pelas quais as instituições de ensino de graduação em Medicina no Brasil vêm passando nos últimos anos - apoiadas notadamente pelos ministérios de Educação e Saúde e fundamentadas principalmente nas $\mathrm{DCN}^{36}$, no Programa de Incentivos a Mudanças Curriculares em Medicina (Promed) ${ }^{43}$ e no Programa Nacional de Reorientação da Formação Profissional em Saúde (Pró-Saúde) ${ }^{44}$-, implantou, em 2005, um projeto de mudança curricular em seu curso médico. A instituição estabeleceu uma proposta pedagógica potencialmente transformadora, ultrapassando o tradicional modelo de formação biomédica, substituindo-o por um paradigma biopsicossocial e ambiental, conforme referido em seu Projeto Pedagógico do Curso de Medicina: "a reestruturação do mundo do ensino e do trabalho a partir da realidade concreta dos sujeitos" (p. 4$)^{45}$. Instituiu, desta feita, em sua matriz curricular, as metodologias ativas de ensino-aprendizagem (Maea) - enfatizando a Aprendizagem Baseada em Problemas $(\mathrm{ABP})^{46}$ - e a inserção de graduandos de Medicina nas UBSF desde o primeiro período a partir de 2005, por meio de convênio preestabelecido com o gestor municipal, destacando-se que essa inserção é o objeto de estudo do presente estudo ${ }^{47,48}$. Ressalta-se que este convênio já vinha sendo celebrado desde 1999, possibilitando a inserção dos estudantes por seis meses — durante o internato médico - nas UBSF.

Com base na vivência deste processo de transformação curricular formulam-se as seguintes indagações: a inserção de estudantes de Medicina desde os primeiros períodos nas UBSF, como realizada pelo Unifeso, é capaz de contribuir para uma nova percepção sobre a saúde e o processo de adoecimento? Qual seria a percepção deste aluno a respeito desta inserção?

Explorar tais indagações - apresentando dados acerca do ponto de vista dos discentes - é o escopo do presente artigo.

\section{MÉTODOS}

A pesquisa qualitativa - com o uso complementar de estratégias quantitativas - representou o percurso metodológico desta investigação. O cenário de pesquisa foi o Unifeso, situado no município de Teresópolis, no Estado do Rio de Janeiro, com discentes matriculados regularmente no quinto período do curso de graduação em Medicina, os quais já possuíam uma boa experiência nos cenários das UBSF e com o uso da ABP.

Foi estabelecida uma amostra definida pelo critério de "saturação de respostas semelhantes ou iguais", conforme destacado por Minayo (p. 209) ${ }^{49}$, ao referir que uma amostra deve responder a normas de validade tais como representati- 
vidade, exaustividade e pertinência. Contemplando tal critério, o número final de estudantes entrevistado foi 29 , dentre todos aqueles matriculados regularmente no quinto período (cerca de $40 \%$ do total, tendo em vista um universo de 72 discentes nesse período). As entrevistas foram realizadas, em sua maior parte, no campus sede do Unifeso, de setembro a novembro de 2008. A pesquisa foi efetuada após a aprovação do projeto de pesquisa pelo Comitê de Ética em Pesquisa do Unifeso - Memorando de Aprovação n⿳0 166/08, de $1^{\circ}$ de julho de 2008 - e da assinatura do Termo de Consentimento Livre e Esclarecido (TCLE) pelos estudantes, sendo garantido o sigilo sobre suas identidades. Ressalte-se, pois, que a pesquisa está em plena consonância com o estabelecido na Resolução 196/96 e suas complementares ${ }^{49,50}$.

A técnica de coleta de dados escolhida foi a aplicação de entrevista individual, contendo as seguintes perguntas abertas: (a) Como tem sido para você participar desde os períodos iniciais das atividades nas UBSF? (b) O que você manteria e o que você modificaria nesta prática dentro das UBSF?

A apreciação das respostas foi conduzida pela técnica de Análise de Conteúdo - mais especificamente a Análise Temática -, devido à sua adequação à investigação qualitativa sobre pesquisas na área da saúde. Foram seguidas as três etapas operacionais da Análise Temática: (a) pré-análise, decomposta em leitura flutuante, constituição do corpus e formulação de hipóteses e objetivos com base nas respostas dos entrevistados; (b) exploração do material; (c) tratamento dos resultados obtidos e interpretação, segundo as orientações de Minayo ${ }^{49}$. Na segunda fase foi incluída a análise das questões empregando-se categorias.

Bardin $^{51}$ define que as categorias seriam rubricas ou classes reunidas em torno de um grupo de elementos definidos também como unidades de registro sob um título genérico e agrupadas em razão de características comuns dos elementos. Refere, ainda, três esferas essenciais para compô-las: (a) pertinência, ou seja, possuir uma ideia de adequação ótima, refletindo as intenções da pesquisa; (b) objetividade; (c) fidelidade, procurando a codificação de uma mesma maneira, evitando a "subjetividade e a variação de juízos" na escolha de categorias. Procurou-se seguir estes princípios na análise das respostas dos entrevistados ${ }^{51}$. Destaque-se que o critério adotado de categorização desta pesquisa foi o semântico, ou seja, procurou-se criar categorias por temas de acordo com as respostas fornecidas ${ }^{51}$.

A análise geral desta pesquisa considerou a frequência absoluta das expressões - termos ou ideias referidos para compor cada categoria - e a combinação do número destas expressões por estudantes, ressaltando, assim, o número de alunos entrevistados e suas categorias referidas em frequência relativa (porcentagem). Tais categorias foram subdivididas em categorias relacionadas a impressões positivas e categorias relacionadas a impressões negativas.

A frequência das categorias com base em suas expressões foi determinada em números absolutos — frequência absoluta (FA) -, conforme se verificará nas tabelas que se seguem. Estas tabelas foram criadas para melhor análise comparativa com a incorporação de frequências relativas (FR) — ou porcentagens arredondadas - dos estudantes e suas respectivas categorias.

Compreende-se que estes números absolutos das categorias também representam o número de entrevistados, uma vez que, pelo princípio da exclusividade na criação de categorias, este termo ou expressão não pode ser utilizado para outra categoria, representando, assim, a expressão de um único entrevistado - ou seja, cada expressão pertence efetivamente a um entrevistado. Ressalte-se que cada entrevistado pode ou não emitir mais de uma expressão e, portanto, a soma final do número de expressões não é necessariamente igual ao número total de entrevistados (no caso: 29). Da mesma forma, a soma da porcentagem destes estudantes não é igual a 100\%, mas uma porcentagem maior que $100 \%$ porque, como já explicado, há sobreposição de expressões para cada um dos estudantes - ou seja, cada entrevistado pode ter mais de uma concepção e, portanto, como referido, expressar mais de uma categoria em sua fala ${ }^{51,52}$.

A análise final deste trabalho considerou a categoria com o maior número de expressões - ou a mais frequente - e a soma das expressões de todas as categorias com sua conotação, positiva ou negativa, para a análise final da questão formulada. Todas estas informações são mais bem elucidadas adiante.

\section{RESULTADOS}

Tomando por base as respostas dos entrevistados, foram criadas duas grandes classificações: categorias de classificação positi$v a$, que têm como categorias representativas: inserção com ressalvas; humanização e integração da teoria e da prática; e categorias de classificação negativa/crítica: preceptoria ausente (entendida como condição de ensinar procedimentos clínicos ou competência clínica), qualidade do profissional; organização da UBSF e má impressão da visita domiciliar.

Foram 20 as expressões de categorias positivas, enfatizando-se que aquela que apresentou a maior frequência foi relativa à "integração teoria/prática". Este aspecto, por si mesmo, é muito positivo, uma vez que o exercício da clínica ampliada - com a sensibilização do discente para aspectos que ultrapassam os livros e a sala de aula, tais como a história subjetiva e social de cada sujeito e sua relação com o meio ambiente, possibilitando de fato a integralidade do cuidado - é elemen- 
to essencial na formação médica. A "inserção com ressalvas" é a segunda categoria positiva mais frequente - ou seja, mesmo sendo positiva a inserção, esta apresenta críticas dirigidas à forma como está sendo feita, embora já seja muito importante o reconhecimento da UBSF como espaço integrador entre a teoria e a prática. Por último, destaca-se a categoria "humanização", que, apesar de referida com menor frequência, deve ser bastante valorizada, pois diz respeito a uma condição crucial para o ato de acolher e cuidar de forma integral.

Foram, então, criadas as categorias de classificação negativa ou crítica, destacando-se os elementos atinentes à organização - mormente planejamento deficiente e comunicação insuficiente entre coordenação e UBSF -, citada 25 vezes, como referido na categoria "organização das UBSF". Verificou-se um total de 47 expressões como categorias negativas. É importante citar que a coordenação à qual se referem os estudantes é vista de forma ambígua, não se identificando uma coordenação / setor específico como foco da queixa. Além deste item, ressalta-se a categoria "preceptoria ausente", citada 12 vezes. Neste aspecto, compreendeu-se a definição de preceptoria de acordo com Botti e Rego ${ }^{53}$ : "a condição de ensinar procedimentos clínicos ou competência clínica" ou ainda "o ensino-aprendizagem do desenvolvimento profissional em situações clínicas reais no próprio ambiente de trabalho" (p. 365). Tais aspectos são específicos da função do médico, como destacado por Houaiss (p. 396 ${ }^{54}$, que define a clínica como o "estudo médico feito sobre o corpo de um doente, ou a prática da medicina" e o clínico como aquele que "se faz junto ao leito do doente". Botti e Rego ${ }^{53}$ ainda identificam no preceptor um papel de "suporte, para ajudar o novo profissional a adquirir prática, até que este tenha maior confiança e segurança em suas atividades diárias"(p. 365), fato que por si só parece justificar sua presença em um cenário de prática como a UBSF. Em síntese, o percentual de estudantes que referem que a UBSF se encontra pouco organizada - categoria "organização das UBSF" é muito elevado (86\%), ou seja, cerca de oito a nove em dez alunos entrevistados, assim como aquele apresentado em relação à necessidade de um preceptor no local (41\%), razoável percentual dos entrevistados.

Foi verificada, ainda, a má impressão daquela que poderia ser considerada uma das mais ricas atividades nas UBSF, a visita domiciliar, por diferentes razões, apontadas no Quadro 4. Seguem os Quadros 3, 4 e 5, relativos, respectivamente, às categorias positivas e negativas criadas de acordo com ideias e/ou expressões referidas na entrevista e sua frequência absoluta, assim como a porcentagem de estudantes que a citaram e ainda a relação final entre as impressões positivas e negativas sobre a questão abordada.

QUADRO 3

Categorias positivas criadas com base em ideias e/ou expressões referidas na entrevista, sua frequência e referência nos estudantes

\begin{tabular}{|c|c|c|c|}
\hline $\begin{array}{c}\text { Categorias } \\
\text { positivas criadas }\end{array}$ & Exemplos de ideias/expressões positivas referidas & $\begin{array}{l}\text { Frequência } \\
\text { absoluta } \\
\text { (n) }\end{array}$ & $\begin{array}{l}\text { Frequência } \\
\text { relativa } \\
(\%)\end{array}$ \\
\hline $\begin{array}{l}\text { Inserção com } \\
\text { ressalvas }\end{array}$ & $\begin{array}{l}\text { "o problema não é a inserção que é boa, mas..." } \\
\text { "acho que obtive conhecimentos com a inserção, mas"; } \\
\text { "proveitosa, mas..."; } \\
\text { "extremamente importante, mas..."; } \\
\text { "muito significativa, porém..."; } \\
\text { "inicialmente era boa, mas..."; } \\
\text { "ir à casa dos pacientes é muito bom mas". }\end{array}$ & 8 & 28 \\
\hline Humanização & $\begin{array}{l}\text { "tem que ter calor humano na medicina, você acaba vendo sofrimento de alguém e, } \\
\text { querendo ou não, acaba aprendendo com ele"; } \\
\text { "analisa o indivíduo, sua vida e a comunidade em que se insere". }\end{array}$ & 2 & 7 \\
\hline $\begin{array}{l}\text { Integração da teoria } \\
\text { e da prática }\end{array}$ & $\begin{array}{l}\text { "muito satisfatória, pois a diferença entre a teoria e a prática consiste em um abismo"; } \\
\text { "muito positiva, fazia o link entre a teoria e a prática, definindo sua verdadeira vocação"; } \\
\text { "verificava quem podia comprar ou não remédios"; } \\
\text { "proporciona a prática precoce"; } \\
\text { "perdi o medo do paciente e aprendemos a conversar com as pessoas"; "desde cedo } \\
\text { convivemos com a realidade da medicina". }\end{array}$ & 10 & 35 \\
\hline Total & & 20 & - \\
\hline
\end{tabular}

Fonte: dados da pesquisa. 


\section{QUADRO 4}

Relação de categorias negativas/críticas criadas com base em ideias e/ou expressões referidas na entrevista, sua frequência e referência nos estudantes

\begin{tabular}{|c|c|c|c|}
\hline $\begin{array}{l}\text { Categorias negativas/ } \\
\text { críticas criadas }\end{array}$ & Exemplos de ideias/expressões negativas referidas & $\begin{array}{l}\text { Frequência } \\
\text { absoluta } \\
\text { (n) }\end{array}$ & $\begin{array}{c}\text { Frequência } \\
\text { relativa } \\
(\%)\end{array}$ \\
\hline $\begin{array}{l}\text { Preceptoria ausente } \\
\text { (condição de ensinar } \\
\text { procedimentos clínicos } \\
\text { ou competência clínica } \\
\text { — ensino-aprendizagem } \\
\text { do desenvolvimento } \\
\text { profissional) }\end{array}$ & $\begin{array}{l}\text { "há necessidade de ter alguém junto a nós na UBSF"; } \\
\text { "o preceptor é fundamental, pois fazer atividades só com o agente comunitário não é tão } \\
\text { rentável"; } \\
\text { "só podia ficar perguntando na VD e não podia fazer um exame físico... meu trabalho era } \\
\text { como de um agente comunitário... faltava um preceptor"; } \\
\text { "nas VDs só ia o agente comunitário quando deveria haver uma recepção melhor... uma } \\
\text { orientação mais profissional"; } \\
\text { "deveríamos discutir e refletir sobre os casos"; "deveria haver um tutor da faculdade na } \\
\text { UBSF"; } \\
\text { "a atenção poderia ser melhor". }\end{array}$ & 12 & 41 \\
\hline Qualidade do médico & "os médicos da UBSF não eram tão bons..." & 1 & 3 \\
\hline Organização da UBSF & $\begin{array}{l}\text { "a estrutura da própria UBSF poderia ser melhor"; } \\
\text { "não tinha muita atividade na UBSF e iamos embora"; } \\
\text { "preenchia o horário somente"; } \\
\text { "muita desorganização na Unidade"; } \\
\text { "a comunicação não é boa entre a faculdade e o aluno"; } \\
\text { "falta comnicação entre a UBSF e a faculdade, e as atividades feitas na UBSF não eram as } \\
\text { que desenvolvíamos nas sessões de tutoria"; } \\
\text { "problemas de comunicação entre a UBSF e a faculdade"; } \\
\text { "tinha que ter um planejamento de atividades na UBS coincidindo com o que aprendemos } \\
\text { no laboratório de habilidades"; } \\
\text { "existe a necessidade de organizar as atividades nas UBSFs"; } \\
\text { "deveria haver atividades predefinidas para os alunos no posto"; } \\
\text { "as atividades desse ambiente deveriam estar programadas com as atividades do período"; } \\
\text { "a atividade na UBSF é pouco efetiva por falta de conhecimento prévio nos períodos } \\
\text { iniciais". }\end{array}$ & 25 & 86 \\
\hline $\begin{array}{l}\text { Má impressão da visita } \\
\text { domiciliar }\end{array}$ & $\begin{array}{l}\text { "achava que o usuário não gostava da visita domiciliar, além de não ser um ambiente } \\
\text { adequado ao exame do paciente"; } \\
\text { "achava que a visita não deveria ser obrigatória"; } \\
\text { "nos dias de VD não havia tanto aprendizado"; } \\
\text { "as minhas atividades nas unidades eram inúteis, eu só fazia VD"; } \\
\text { "a VD não me acrescentava nada e era cansativa"; } \\
\text { "melhorou quando parei de fazer VD"; } \\
\text { "tiraria a VD e colocaria os alunos só acompanhando consultas". }\end{array}$ & 9 & 31 \\
\hline Total & & 47 & - \\
\hline
\end{tabular}

Fonte: dados da pesquisa.

QuAdRO 5

Relação entre as impressões positivas e negativas referidas

\begin{tabular}{|l|c|c|c|}
\hline \multicolumn{1}{c|}{$\begin{array}{c}\text { Questão: } \\
\text { “Práticas nas UBSF” }\end{array}$} & Expressões positivas & Expressões críticas/negativas & Total \\
\hline Frequência absoluta & 20 & 47 & 67 \\
\hline Frequência relativa & $30 \%^{*}$ & $70 \%^{*}$ & $100 \%$ \\
\hline
\end{tabular}

* Porcentagem obtida com base na relação entre a frequência absoluta de cada uma destas expressões e o número total de expressões.

Fonte: dados da pesquisa. 
A reflexão sobre os dados obtidos é apresentada a seguir, de acordo com os referenciais teóricos propostos.

\section{DISCUSSÃO}

Com base nos resultados foi possível identificar que, na visão dos entrevistados, as atividades nas UBSF deixam uma impressão negativa em relação à formação médica, ainda que também se indiquem pontos positivos. Destaque-se a desorganização das unidades - aspecto já apontado em outras investigações ${ }^{55,56}$ - e a necessidade de um preceptor local, embora se reconheça que a integração entre teoria e prática seja bastante positiva. Percebe-se que a inserção precoce em UBSF apresenta problemas, tornando-as um cenário inadequado de aprendizagem devido a questões estruturais da própria ESF e à insuficiente conversação entre esta e a instituição, de modo a se aprimorar a integração ensino-serviço-comunidade. A ausência de um efetivo preceptor local é também fator problemático, de acordo com os entrevistados. Neste sentido, é importante ressaltar que o contato horizontal com a figura do preceptor é relevante para a criação de vínculo entre o estudante e o usuário/comunidade, facilitando, assim, seus primeiros passos de ensino-aprendizagem na área da saúde e auxiliando seu processo emancipatório, tornando-o, paulatinamente, um sujeito ativo, questionador e transformador da realidade em que está inserido.

Algumas considerações a respeito desta percepção negativa das UBSF podem ser justificadas pela reduzida oferta de atenção da equipe ao estudante, originada pela sobrecarga de trabalho, oriunda, entre outras causas, do elevado número de famílias adscritas - o que, em última análise, é mais um elemento de precarização do trabalho na $\mathrm{ESF}^{57}$. Esse número elevado de assistidos se explica em parte pela falta de expansão do PSF no município - atualmente com cerca de 30\% de cobertura $^{58}$-, o que acarreta, por exemplo, maior complexidade na organização do trabalho destas equipes, destacando-se o número elevado de consultas por demanda programada e espontânea e de visitas domiciliares. Assim, a falta de identificação de um preceptor local — um membro da ESF dependendo da organização de cada equipe - acaba por provocar uma falta de reconhecimento daquele cenário como potencializador do ensino-aprendizagem na formação do estudante ${ }^{59-64}$.

Outro aspecto a considerar é que os problemas apresentados na inserção em UBSF podem também ser justificados em parte pelas diferentes ofertas de recursos físicos, técnicos e humanos para ensino-aprendizagem nos módulos que compõem a estrutura curricular do curso de graduação em Medicina do Unifeso: os módulos tutorial (MT) e de prática profissional (MPP). A possibilidade de organização mais eficiente do MT
— já que este abrange um cenário teórico (tutorias, as quais têm por objetivo estimular o estudante a conquistar autonomia para a busca da informação científica, com base em problemas apresentados em sete passos ou etapas) e um cenário simulado (laboratório de habilidades, no qual os estudantes, sob supervisão de um professor, desenvolvem técnicas de comunicação e habilidades semiotécnicas em manequins) -, em contraste com os cenários de trabalho vivo do MPP, pode também explicar o desencanto dos estudantes com a UBSF. De fato, o MPP - cujo objetivo é favorecer o desenvolvimento de habilidades para a clínica ampliada, incluindo vários cenários, além da própria UBSF e do hospital da instituição — apresenta enormes diferenças entre sua estrutura física, sua organização e seus recursos humanos: trata-se do SUS vivo, com todas as suas contradições e idiossincrasias ${ }^{59-65}$.

Além desses pontos relacionados ao processo de trabalho das equipes das UBSF - que, certamente, influenciam o ensino-aprendizagem -, é importantíssimo verificar como as competências sugeridas para serem desenvolvidas nestes cenários podem ser realmente adquiridas, o que também pode justificar o descontentamento dos estudantes, mormente em um contexto em que a equipe não consegue dar conta dos problemas de saúde da coletividade ${ }^{60,61}$. Nestes termos, estudos como o de Gil et al. (p. 234 e 238) ${ }^{66}$, realizado com base em vivências nos cenários de prática com graduandos em Medicina da Universidade Estadual de Londrina (UEL), apresentam resultados semelhantes aos do presente trabalho, na medida em que se reconhece que a inserção dos estudantes na atenção primária encontra diversos desafios, tais como: (a) os diferentes tempos institucionais dos serviços e do ensino para atender às necessidades de saúde da comunidade, gerando pouco tempo para as práticas com os estudantes; (b) adesão diminuída dos estudantes, por ainda não possuírem habilidades e atitudes que contribuam para o cuidado perante a demanda existente nos serviços, gerando frustrações e a genuína "sensação de que atrapalham o serviço"; (c) "falta de tempo dos profissionais de saúde para os estudantes aí inseridos", além da perda do significado das visitas domiciliares feitas por estudantes, os quais se orientam predominantemente para o diagnóstico dos problemas de saúde da comunidade, sem uma proposta de solução. Esses autores também apontam a necessidade de ofertar formação em Maea aos profissionais que se interessassem pela preceptoria e estabelecer uma gratificação diferenciada para eles ${ }^{66}$

Como resposta aos desafios expostos e analisados neste trabalho, a Associação Brasileira de Educação Médica (Abem) e a Sociedade Brasileira de Medicina de Família e Comunidade (SBMFC), desde 2005, promoveram fóruns de discussão, 
QUADRO 6

Relação das Diretrizes para o Ensino na Atenção Primária à Saúde na Graduação em Medicina

\begin{tabular}{|c|c|c|c|c|c|c|}
\hline $\begin{array}{l}\text { Temática } \\
\text { abordada }\end{array}$ & $\begin{array}{l}\text { Contribuições da Atenção } \\
\text { Primária à Saúde para a } \\
\text { graduação em Medicina }\end{array}$ & $\begin{array}{l}\text { Objetos de } \\
\text { ensino- } \\
\text { aprendizagem }\end{array}$ & $\begin{array}{l}\text { Momentos } \\
\text { formativos }\end{array}$ & $\begin{array}{c}\text { Diretriz metodológica } \\
\text { e estratégia didática }\end{array}$ & $\begin{array}{c}\text { Espaços } \\
\text { formativos }\end{array}$ & $\begin{array}{l}\text { Docentes e } \\
\text { preceptores }\end{array}$ \\
\hline Pergunta & Por quê? & O quê? & Quando? & Como? & Onde? & Quem? \\
\hline Exemplos & $\begin{array}{l}\text { Contextualização com a } \\
\text { realidade local }\end{array}$ & $\begin{array}{l}\text { Primeiro } \\
\text { contato com o } \\
\text { paciente }\end{array}$ & $\begin{array}{l}\text { Inserção } \\
\text { longitudinal em } \\
\text { todos os } \\
\text { períodos }\end{array}$ & $\begin{array}{l}\text { Estratégia } \\
\text { significativa e } \\
\text { dialógica com } \\
\text { integração } \\
\text { ensino-teoria }\end{array}$ & $\begin{array}{l}\text { Unidades de } \\
\text { Saúde da } \\
\text { Família } \\
\text { acessíveis }\end{array}$ & $\begin{array}{l}\text { Equipe e Médico } \\
\text { especialista em } \\
\text { MFC }\end{array}$ \\
\hline
\end{tabular}

como os realizados no $44^{\circ}$ Congresso Brasileiro de Educação Médica, em 2006, e no IX Congresso Brasileiro de MFC, em 2008, para apoiar as escolas em seu processo de mudança. Finalmente, em 2011, a Revista Brasileira de Medicina de Família e Comunidade ${ }^{67,68}$ publicou um conjunto de diretrizes construídas pela Abem e SBMFC - Diretrizes para o Ensino na Atenção Primária à Saúde na Graduação em Medicina (D-APS) -, com o objetivo de apoiar as escolas médicas na elaboração de projetos pedagógicos no contexto da Atenção Primária à Saúde. Essas diretrizes são apontadas de forma sintética no Quadro 6, que demonstra os pressupostos exemplificados para o ensino na APS e indagações correlatas ${ }^{67,68}$.

É importante permitir que o estudante de Medicina que se encontra, hoje, diante de um novo modelo curricular constituído por Maea e por novos cenários de ensino-aprendizagem - se torne o egresso apontado pelas DCN. Para isto, propõe-se sua inserção na Atenção Primária à Saúde, com base na noção da integralidade do cuidado, centrada em seu abrangente conceito de adoecer biopsicossocioambiental, contextualizada, inscrita na aprendizagem significativa ${ }^{69}$ e justificada pelas questões: Por quê? — O quê? — Quando? - Onde? Quando? e Quem? e respectivas propostas das Diretrizes para o Ensino na APS" 68 , conforme mostrado na Figura 1.

Desta forma, é de fundamental importância que as escolas médicas estejam atentas às díspares experiências de integração ensino-trabalho-comunidade - tal como a presentemente descrita - e que as percepções dos estudantes e dos usuários do SUS sejam consideradas como referência para melhor adequação de ensino-aprendizagem nestes cenários, uma vez que esta inserção pode se tornar um efetivo instrumento de integração e sensibilização para a realidade local daquela comunidade, consolidando, assim, o sucesso de uma real transformação curricular.

É importante ressaltar, ainda, que as visitas domiciliares podem representar e contextualizar este conceito de integrali-
FIGURA 1

Diagrama da inter-relação entre o conceito de integralidade e as Diretrizes para o Ensino na APS

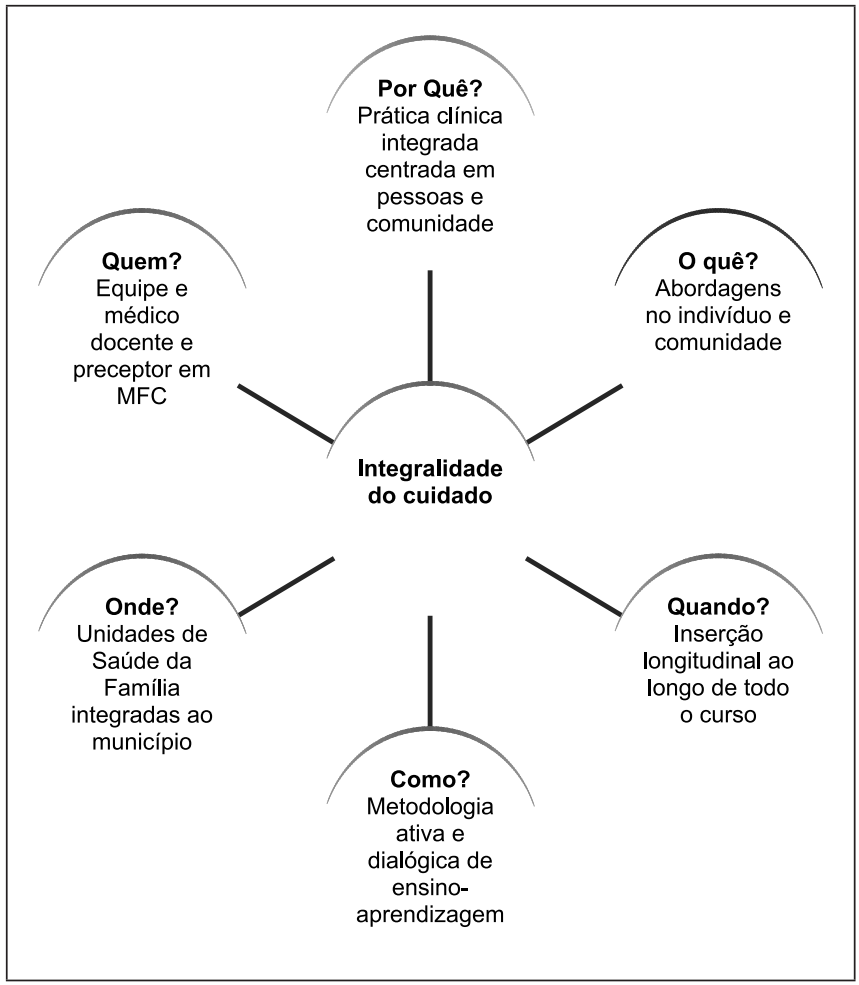

Fonte: Elaboração teórica dos autores, sob inspiração de Gusso G, Marins JJN Demarzo MMP, Belaciano MI, Almeida RCC, Stein AT et al., orgs. Diretrizes para o ensino na Atenção Primária à Saúde na graduação em Medicina (SBMFC e Abem). [Captado em 27 de abril de 2012]. Disponível em: http:/ / www.abem-educmed.org.br/pdf/atencao_primaria_caderno05.pdf.

dade e a aplicação das propostas presentes nas D-APS. Tal atividade pode apresentar ao discente uma gama de sinais que se constituem na vida pulsátil. De fato, as moradias, as ruas e as ruelas, a comunidade, o bairro, sua urbanização e sua integração à cidade interagem continuamente com a saúde das pesso- 
as e tornam as vidas extensão e metáfora deste cenário. A educação médica não pode, definitivamente, prescindir dessa vivência. Aqui pode estar em jogo o lídimo despertar da vocação profissional deste estudante.

\section{CONSIDERAÇÕES FINAIS}

A Estratégia Saúde da Família pode representar para a educação médica muito mais do que um cenário vivo, talvez a própria vida em forma de diferentes cenários, indispensáveis, embora muitas vezes desconfortáveis. Trata-se de mais uma manifestação da existência que não pode ser colocada de lado, excluída e ocultada das doutas vistas, principalmente no caso daqueles que já atuam junto aos usuários e que irão tratar deles ainda mais no futuro: os estudantes de Medicina. É de fundamental importância que estes sejam capazes de perceber que todo e qualquer processo de adoecimento está, de algum modo, aí contextualizado.

No município de Teresópolis, é visível, de algumas UBSF, o Dedo de Deus, atração turística do Parque Nacional da Serra dos Órgãos. A profusão de moradias que invadem, pouco a pouco, as montanhas e as matas - assim como a floresta remanescente local, a Mata Atlântica, degradando-a e ferindo-a — não deixa dúvidas sobre a maneira como se pode viver e como, ainda que pareça sem opções, se pode adoecer e morrer, como ocorrido nas recentes tragédias climáticas de 12 de janeiro de 2011 e de 6 de abril de 2012, que custaram as vidas de centenas de moradores das encostas ${ }^{70,71,72}$.

Integrar os discentes de Medicina nesses cenários é uma grande responsabilidade social das instituições de ensino e da sociedade brasileira. Já para o docente e as equipes das UBSF, cabe o papel de acolhimento - manifestação de ternura -, e ao estudante, muito mais do que ensino-aprendizagem, a disposição para vivenciar uma oportunidade singular de perceber a complexidade dos fenômenos do viver, do adoecer e do morrer de mulheres e homens. Quiçá todos saibam aproveitá-la!

\section{REFERÊNCIAS}

1. Almeida MJ. Educação Médica e Saúde: possibilidades de mudança. Londrina: UEL, Rio de Janeiro: ABEM; 1997.

2. Lampert JB. Tendências de Mudança na Formação Médica no Brasil: tipologia das escolas. São Paulo: Hucitec/ABEM; 2002.

3. Gomes AP, Rego S. Transformação da educação médica: é possível formar um novo médico a partir de mudanças no método de ensino-aprendizagem? Rev Bras Educ Méd. 2011;35(4):557-566.

4. Feuerwerker LCM. Gestão dos Processos de Mudança na Graduação em Medicina. In: Marins JJN, Rego S, Lampert
JB, Araújo JGC, orgs. Educação médica em transformação, instrumentos para a construção de novas realidades. São Paulo: Hucitec; 2004. p.17-39.

5. Ceccim R, Feuerwerker LCM. O quadrilátero da formação para a Área da Saúde: Ensino, Gestão, Atenção e Controle Social. PHYSIS. 2004;14(1):41-65.

6. Marins JJN. Os Cenários de Aprendizagem e o Processo do Cuidado em Saúde. In: Marins JJN, Rego S, Lampert JB, Araújo JGC, orgs. Educação médica em transformação: instrumentos para a construção de novas realidades. São Paulo: ABEM/HUCITEC; 2004. p.97-108.

7. Bittencourt-Costa JR, Romano VF, Costa RR, Gomes AP, Siqueira-Batista R. Active teaching-learning methodologies: medical students' views of problem-based learning. Rev Bras Educ Méd. 2011;35(1):13-19.

8. Koifman L, Saippa-Oliveira G. As práticas de avaliação da formação e do cuidado orientadas pela integralidade: uma aproximação necessária In: Pinheiro, R, Mattos RA. Gestão em redes: práticas de avaliação, formação e participação na saúde. Rio de Janeiro: CEPESC — ABRASCO; 2006. p. 245-260.

9. Gomes AP, Arcuri MB, Cristel EC, Ribeiro RM, Souza LBM, Siqueira-Batista R. Avaliação no Ensino Médico: o papel do portfólio nos currículos baseados em metodologias ativas. Rev Bras Edu Méd. 2010;34(3):390-396.

10. Ceccim R, Capozzolo AA. Educação dos Profissionais de Saúde e Afirmação da Vida: a Prática Clínica como Resistência e Criação. In: In: Marins JJN, Rego S, Lampert JB, Araújo JGC, orgs. Educação médica em transformação: instrumentos para a construção de novas realidades. São Paulo: ABEM/HUCITEC; 2004. p.346-90.

11. Santos BS. Um discurso sobre as ciências. Porto: Afrontamento; 2002.

12. Siqueira-Batista R, Helayël-Neto JA. The chance is necessary? The case of The Drunkard's Walk: How Randomness Rules Our Lives. Rev Bras Ens Fis. 2011; 33(3):1-1.

13. Maturana H, Varela F. De máquinas e seres vivos. Autopoiese, a Organização do Vivo. Porto Alegre: Artes Médicas; 1997.

14. Siqueira-Batista R. Infinito íntimo: eutanásia e libertação. In: Carvajal E, Moraes PFC, Pegoraro AO, orgs. Células-tronco e eutanásia: potencialidades e limites. Rio de Janeiro: EdUERJ; 2009. p. 105-128.

15. Pinheiro R, Ceccim RB, Mattos RA, orgs. Ensino-Trabalho-Cidadania: novas marcas ao ensinar integralidade no SUS. Rio de Janeiro: IMS/UERJ: CEPESC: ABRASCO; 2006.

16. Silveira R, Leal O, Lofego J. Saúde da Família no Curso de Medicina da Universidade Federal do Acre. In: Pinheiro R, 
Ceccim RB, Mattos RA, orgs. Ensino-Trabalho-Cidadania: novas marcas ao ensinar integralidade no SUS. Rio de Janeiro: IMS/UERJ: CEPESC: ABRASCO; 2006. p. 15-32.

17. Moura A, Miranda MGO, Lima MGA, Filho JB. O desafio da construção de marcos teóricos e metodológicos (re) orientadores da produção da força de trabalho de enfermagem no espaço da FAEN. In: Pinheiro R, Ceccim RB, Mattos RA, orgs. Ensino-Trabalho-Cidadania: novas marcas ao ensinar integralidade no SUS. Rio de Janeiro: IMS/ UERJ: CEPESC: ABRASCO; 2006. p. 33-44.

18. Borba PC. A Saúde da Família na Faculdade de Medicina de Juazeiro do Norte. In: In: Pinheiro R, Ceccim RB, Mattos RA, orgs. Ensino-Trabalho-Cidadania: novas marcas ao ensinar integralidade no SUS. Rio de Janeiro: IMS/UERJ: CEPESC: ABRASCO; 2006. p. 45-56.

19. Cabral PE, Koadjaoglaniam VL, Barbier CP, Freitas LSS, Novaes CJ, Mattos MCI. Interação Ensino-Serviço-Comunidade uma ferramenta para a integralidade. In: Pinheiro R, Ceccim RB, Mattos RA, orgs. Ensino-Trabalho-Cidadania: novas marcas ao ensinar integralidade no SUS. Rio de Janeiro: IMS/UERJ: CEPESC: ABRASCO; 2006. p. 57-70.

20. Cyrino EG, Martins STF, Preto AY, Manoel CM, Oikawa LT, Vecchia MD, Romanholi RMZ, Uliana MR. Em busca da recomposição da arte de do cuidado e do fazer/aprender: a interação universidade, serviço, e comunidade na Faculdade de Medicina de Botucatu/UNESP. In: Pinheiro R, Ceccim RB, Mattos RA, orgs. Ensino-Trabalho-Cidadania: novas marcas ao ensinar integralidade no SUS. Rio de Janeiro: IMS/UERJ: CEPESC: ABRASCO; 2006. p. 71-84.

21. Ferreira e Ferreira E, Vargas AMD, Amaral JHL, Vasconcelos M, Mattos FF. Travessia a caminho da integralidade: uma experiência do Curso de Odontologia da UFMG. In: Pinheiro R, Ceccim RB, Mattos RA, orgs. Ensino-Trabalho-Cidadania: novas marcas ao ensinar integralidade no SUS. Rio de Janeiro: IMS/UERJ: CEPESC: ABRASCO; 2006. p. 85-92.

22. Brito MJM, Madeira LM, Mendes LC, Lopes TC, Dittz ES. Experiências da integralidade no curso de graduação da Escola de Enfermagem da Universidade Federal de Minas Gerais. In: Pinheiro R, Ceccim RB, Mattos RA, orgs. Ensino-Trabalho-Cidadania: novas marcas ao ensinar integralidade no SUS. Rio de Janeiro: IMS/UERJ: CEPESC: ABRASCO; 2006. p. 93-108.

23. Dellaroza MSG, Trelha CS, Yamada KN, Cabreira MAS. Projeto de Assistência Interdisciplinar ao Idoso em nível Primário (PAINP): a busca de uma prática possível. In: Pinheiro R, Ceccim RB, Mattos RA, orgs. Ensino-Trabalho-Cidadania: novas marcas ao ensinar integralidade no SUS. Rio de Janeiro: IMS/UERJ: CEPESC: ABRASCO; 2006. p. 109-122.
24. Budó MLD, Ressel LB, Beck CLC, Colomé CLM, Amaraim IK, Poppi MC, Machado TS, Dornelles CS. O Diagnóstico de saúde em unidade de saúde da família como ferramenta prática pedagógica. In: Pinheiro R, Ceccim RB, Mattos RA, orgs. Ensino-Trabalho-Cidadania: novas marcas ao ensinar integralidade no SUS. Rio de Janeiro: IMS/UERJ: CEPESC: ABRASCO; 2006. p. 123-136.

25. Stedile MO, Claus SM. Uma proposta inovadora de formação de profissional em fisioterapia centrada na integralidade em saúde - Propostas de transformação. In: Pinheiro R, Ceccim RB, Mattos RA, orgs. Ensino-Trabalho-Cidadania: novas marcas ao ensinar integralidade no SUS. Rio de Janeiro: IMS/UERJ: CEPESC: ABRASCO; 2006. p. 137-153.

26. Pinheiro R, Ceccim RB, Mattos RA, orgs. Ensino-Trabalho-Cidadania: novas marcas ao ensinar integralidade no SUS. Rio de Janeiro: IMS/UERJ: CEPESC: ABRASCO; 2006.

27. Rego S, Gomes AP, Siqueira-Batista R. Bioética e humanização como temas transversais na formação médica. Rev Bras Educ Méd. 2008;32(4):482-491.

28. Macedo MCS, Romano RAT, Henriques RLM. Transformação na graduação de enfermagem da UERJ. In: Pinheiro R, Ceccim RB, Mattos RA, orgs. Ensinar saúde: a integralidade e o SUS nos cursos de graduação na área da saúde. Rio de Janeiro: IMS/UERJ CEPESQ ABRASCO; 2006. p.278-94.

29. March C, Koifman L, Pontes ALM, Saippa-Oliveira G, Júnior AGS, Fernandez VS. O currículo de medicina da Universidade Federal Fluminense: revisitando uma experiência. In: Pinheiro R, Ceccim RB, Mattos RA, orgs. Ensinar saúde: a integralidade e o SUS nos cursos de graduação na área da saúde. Rio de Janeiro: IMS/UERJ CEPESQ ABRASCO; 2006. p. 295-309.

30. Netto Cézar PH, Guimarães FT, Gomes AP, Rôças G, Siqueira-Batista R. Transição paradigmática na educação médica: um olhar construtivista dirigido à aprendizagem baseada em problemas. Rev Bras Educ Méd. 2010;34(2):298303.

31. Ferreira RC, Silva RF, Agner CB. Formação do Profissional Médico: a Aprendizagem da Atenção Básica de Saúde. Rev Bras Educ Méd. 2007;31(1);52-59.

32. Ferreira RC, Fiorini VML, Crivelaro E. Formação profissional no SUS: o papel da Atenção Básica em Saúde na perspectiva docente. Rev Bras Educ Méd. 2010; 34(2):207-215.

33. Bulcão LG. O Ensino Médico e os Novos Cenários de Ensino-Aprendizagem. Rev Bras Educ Méd 2004:28(1):61-72

34. Gil CRR, Turini B, Cabrera MAS, Kohatsu M, Orquiza $\mathrm{SMC}$. Integração ensino, serviços e comunidade: desafios e 
perspectivas na atenção básica. Rev Bras Educ Méd. 2008;32(2):230-239.

35. Brasil. Departamento de Atenção Básica. Atenção Básica e a Saúde da Família. Diretriz Conceitual. [Capturado em 03 de dezembro de 2010]. Disponível em: http://www. dtr2004.saude.gov.br/dab/atencaobasica.php.

36. Brasil. Ministério da Educação. Conselho Nacional de Educação. Câmara de Educação Superior. Resolução n . 4, de 7 de novembro de 2001. Institui Diretrizes Curriculares Nacionais do Curso de Graduação em Medicina. Diário Oficial da União, Brasília, 9 de novembro de 2001; Seção 1, p. 38.

37. Starfield B. Atenção Primária. Equilíbrio entre as necessidades de saúde, serviços e tecnologia. Brasília: UNESCO, Ministério da Saúde; 2002.

38. World Health Organization. Primary care. Genebra: WHO, 1978. [Capturado em 10 de janeiro de 2010]. Disponível em: http://www.who.int/es/index.html.

39. Miranda JFA. Estudo do Impacto da Adoção da Estratégia da Saúde da Família no Internato Médico. Educação Médica. Rio de Janeiro: Papel Virtual Editora, 2004.

40. Campos GWS. Papel da Rede de Atenção Básica em Saúde na Formação Médica — Diretrizes:documento preliminar — abril de 2005. [online]. [Capturado 10 setebro de 2008]. Disponível em: http:/ /www.abem-educmed.org.br/pdf/ doc_prof_gastao.pdf.

41. Cordeiro H. Os desafios do ensino das profissões de saúde frente às mudanças do modelo assistencial: contribuição para além dos Pólos de Capacitação. Rev Ensaio: Aval Pol Públ Educ. 2002;10(34):43-54.

42. Siqueira-Batista R, Rôças G. Alfabetização ecológica. Rev Bras Educ Méd. 2009;33(1):123-125.

43. Brasil. Ministério da Saúde. Ministério da Educação. Organização Panamericana da Saúde. PROMED - Programa de Incentivo a Mudanças Curriculares nos Cursos de Medicina. Brasília: Secretaria de Políticas da Saúde; 2002. [Edital de Convocação].

44. Brasil. Ministério da Saúde. Ministério da Educação. Programa Nacional de Reorientação da Formação Profissional em Saúde - PRÓ-SAÚDE: objetivos, implementação e desenvolvimento potencial / Ministério da Saúde, Ministério da Educação. -. Brasília - DF, 2007.

45. Fundação Educacional Serra dos Órgãos. O Projeto de Mudança Curricular do Curso de Medicina da FESO. Teresópolis: Faculdades Unificadas; 2004. [mimeo].

46. Siqueira-Batista R, Batista RS. Os anéis da serpente: a aprendizagem baseada em problemas e as sociedades de controle. Ciên Saude Coletiva 2009; 14(4):1183-1192.
47. Fundação Educacional Serra dos Órgãos. Projeto Político-Pedagógico Institucional do Centro Universitário Serra dos Órgãos. Teresópolis: UNIFESO; 2006.

48. Teresópolis. Convênio 005/1999 (PMT/FESO). Regulamenta a realização de estágio supervisionado, 1999.

49. Minayo MCS. O Desafio do Conhecimento - Pesquisa qualitativa em saúde. 6. ed. São Paulo - Rio de Janeiro: HUCITEC-ABRASCO; 1999.

50. Brasil. Resolução 196/96. Conselho Nacional de Diretrizes e Saúde. Normas regulamentadoras das pesquisas envolvendo seres humanos. [Capturado em 07 de fevereiro de 2008]. Disponível em: http://www.ufrgs.br/bioética/ res.19696.htm.

51. Bardin L. Análise de Conteúdo. 3aㅗ ed. Lisboa: Edições 70; 2004.

52. Gomes R. A analise de dados em pesquisa qualitativa. In: Minayo MCS, Deslandes SF, Neto OC, Gomes R. Pesquisa social: teoria, método e criatividade. Petrópolis, RJ: Vozes; 1994. p.67-80.

53. Botti SHO, Rego S. Preceptor, supervisor, tutor e mentor: quais são seus papéis? Rev Bras Educ Med. 2008;32(3):363373.

54. Houaiss A, Koogan A. Enciclopédia e Dicionário Ilustrado. Rio de Janeiro: Edições Delta, 2001.

55. Junqueira TS, Cotta RMM, Gomes RC, Silveira SFR, Siqueira-Batista R, Pinheiro TMM, Melo EM. Saúde, democracia e organização do trabalho no contexto do Programa de Saúde da Família: desafios estratégicos. Rev Bras Educ Med. 2009;33(1):122-133.

56. Martins PC, Cotta R, Mendes FF, Priore SE, Franceschini SCC, Cazal MM, Siqueira-Batista R. De quem é o SUS? Sobre as representações sociais dos usuários do Programa Saúde da Família. Cien Saúde Coletiva. 2011;16(3):19331942.

57. Junqueira TS, Cotta RMM, Gomes RC, Silveira SFR, Siqueira-Batista R, Pinheiro TMM, Sampaio RF. As relações laborais no âmbito da municipalização da gestão em saúde e os dilemas da relação expansão/precarização do trabalho no contexto do SUS. Cad Saúde Pública. 2010;26(5):918928.

58. Brasil. Ministério da Saúde. Teto, credenciamento e implantação das estratégias de Agentes Comunitários de Saúde, Saúde da Família e Saúde Bucal. [Captado em 03 de março de 2012]. Disponível em: http:/ / dab.saude.gov.br/ historico_cobertura_sf/historico_cobertura_sf_relatorio. php.

59. Costa JRB. Análise da atuação das equipes do Programa de Saúde da Família no município de Teresópolis após a mu- 
dança curricular do curso de Medicina da Fundação Educacional Serra dos Órgãos, com a inserção precoce dos alunos: impressão dos médicos e enfermeiros. In: Moço ETSM, Falcão HBPT, Miranda JFA. Reflexões sobre as Mudanças Curriculares na Área de Saúde: Ativando Processos. Rio de Janeiro: Publit; 2007. p. 35-53

60. Unifeso. Cietc. Relatório da oficina de reorganização da atenção básica em saúde do município de Teresópolis. Teresópolis RJ: 2007, CD-ROM.

61. Unifeso. Cietc. Documento da Coordenação de Estruturação de Atividades de Inserção na Comunidade para a Coordenação Atividades de Educação Permanente nas UBSF.

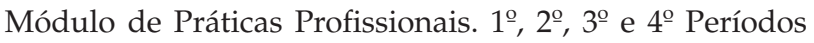
(2007-1). Teresópolis: 2007. [mimeo].

62. Unifeso. Cietc. Planejamento de Atividades do Módulo de Práticas Profissionais/ Cenários Vivos. $-1^{\circ}, 2^{\circ}, 3^{\circ} \mathrm{e} 4^{\circ} \mathrm{Pe}-$ ríodos (2008-1). Teresópolis: 2008. [mimeo].

63. Unifeso. Cietc. Planejamento de Atividades do Módulo de Práticas Profissionais/ Cenários Vivos. $-1^{\circ}, 2^{\circ}, 3^{\circ}$ e $4^{\circ}$ Períodos (2008-2). Teresópolis: 2008, CD-ROM.

64. Santos SS, Siqueira-Batista R, Gomes AP, Almeida LC, Oliveira LB, Farinazzo RJM, Pettendorfer S, Pinto LFS. Avaliação da progressão cognitiva no internato de clínica médica. Rev Bras Educ Med. 2008; 32(3):390-395.

65. Centro Universitário Serra dos Órgãos. Centro de Ciências da Saúde; Curso de Graduação em Medicina; Manual do Tutor/Instrutor; $1^{\circ}$, 2으, $3^{\circ}$ e $4^{\circ}$ períodos; Teresópolis RJ: 2007. CD-ROM

66. Gil CRR, Turini B, Cabrera MAS, Kohatsu M,Orquiza SMC. Interação ensino, serviços e comunidade: desafios e perspectivas de uma experiência de ensino-aprendizagem na atenção básica. Rev Bras Educ Méd. 2008;32(2):230-239.

67. Gusso G, Marins JJN, Demarzo MMP, Belaciano MI, Almeida RCC, Stein AT, orgs. Diretrizes para o ensino na Atenção Primária à Saúde na graduação em Medicina (SBMFC e Abem). [Captado em 27 de abril de 2012]. Disponível em: http://www.abem-educmed.org.br/pdf/atencao_primaria_caderno05.pdf.
68. Demarzo MMP, Almeida RCC, Marins JJN, Trindade TG, Anderson MIP, orgs. Diretrizes para o ensino na Atenção Primária à Saúde na graduação em Medicina. Rev Bras Med Fam e Com. 2011:6(19):145-50.

69. Gomes AP, Dias Coelho UC, Cavalheiro PO, Siqueira-Batista R. O Papel dos Mapas Conceituais na Educação Médica. Rev Bras Educ Med. 2011;35(2):275-282.

70. Portal SOS Mata Atlântica. [Captado em 27 de abril de 2012]. Disponível em: http:/ / www.sosmatatlantica.org.br/

71. O Globo. Tragédia das chuvas deixa ao menos 440 mortos no RJ. [Captado em 27 de abril de 2012]. Disponível em: http:/ /oglobo.globo.com/politica/tragedia-das-chuvas-deixa-ao-menos-440-mortos-no-rj-2837907

72. Zero Hora Disponível em: http://zerohora.clicrbs.com. $\mathrm{br} / \mathrm{rs} /$ noticia/2012/04/chuvas-deixam-pelo-menos-cinco-mortos-na-regiao-serrana-do-rio-de-janeiro-3719803. html

\section{CONTRIBUIÇÃO DOS AUTORES}

O estudo foi desenhado por José Roberto Bittencourt Costa, sob a orientação de Valéria Ferreira Romano. José Roberto Bittencourt Costa, Rosane Rodrigues Costa e Rodrigo Roger Vitorino participaram da coleta de dados e da primeira elaboração do texto. Luiz Anastácio Alves, Valéria Ferreira Romano, Andréia Patrícia Gomes e Rodrigo Siqueira-Batista participaram da revisão crítica e da redação final do artigo.

\section{CONFLITO DE INTERESSES}

Não há conflito de interesses.

\section{ENDEREÇO PARA CORRESPONDÊNCIA}

José Roberto Bittencourt Costa

Coordenação de Medicina

Centro Universitário Serra dos Órgãos - UNIFESO

Avenida Alberto Torres, 111 - Alto.

Teresópolis - RJ-

CEP: 25964-004

E-mail: zeroberto@ioc.fiocruz.br 